\title{
Heat-not-burn tobacco, electronic cigarettes, and combustible cigarette use among Japanese adolescents: a nationwide population survey 2017
}

Yuki Kuwabara ${ }^{* *}$ D, Aya Kinjo', Maya Fujii', Aya Imamoto', Yoneatsu Osaki', Maki Jike², Yuichiro Otsuka², Osamu Itani ${ }^{2}$, Yoshitaka Kaneita ${ }^{2}$, Ruriko Minobe ${ }^{3}$, Hitoshi Maezato ${ }^{3}$, Susumu Higuchi ${ }^{3}$, Hisashi Yoshimoto ${ }^{4}$ and Hideyuki Kanda ${ }^{5}$

\begin{abstract}
Background: From among the global public health concerns, smoking remains one of the most crucial challenges. Especially for adolescents, the increase in the use of electronic cigarettes is controversial, as its use may lead to established smoking. In Japan, where a unique tobacco regulation system exists, the heat-not-burn tobacco market has been growing. However, the prevalence and association of combustible cigarettes and new tobacco-related products have not yet been closely investigated among Japanese adolescents. This study aimed to clarify the prevalence of smoking among adolescents, including new types of tobacco-related products, and to compare the characteristics of their users.

Methods: The 2017 Lifestyle Survey of Adolescents is a nationally-representative survey collected in Japan. From the national school directory, 98 junior high schools and 86 high schools were randomly sampled throughout Japan. The students completed an anonymous questionnaire at school. We calculated the prevalence of use for each type of tobacco product. Then, the use of a combination of products and the characteristics of different types of products were examined.

Results: In total, 64,152 students from 48 junior high schools and 55 high schools were included the analysis (school response rate $=56 \%, M_{\text {age }}=15.7$ years, $53.9 \%$ boys). The age-adjusted rate of ever (current) use of electronic cigarettes was $2.1 \%(0.7 \%)$ in junior high school and 3.5\% (1.0\%) in high school; that of combustible cigarettes was $2.6 \%(0.6 \%)$ in junior high school and $5.1 \%(1.5 \%)$ in high school. The rate of heat-not-burn tobacco use was lower relative to other products: $1.1 \%(0.5 \%)$ in junior high school and $2.2 \%(0.9 \%)$ in high school. An examination of the combined use of the three products identified a high number of dual users. Comparisons between different types of users indicated different backgrounds for combustible cigarette users and new product users.

(Continued on next page)
\end{abstract}

\footnotetext{
* Correspondence: ykuwabara@tottori-u.ac.jp

${ }^{1}$ Division of Environmental and Preventive Medicine, Department of Social

Medicine, Faculty of Medicine, Tottori University, Nishi-machi 86, Yonago-shi,

Tottori 683-8503, Japan

Full list of author information is available at the end of the article
}

C C The Author(s). 2020 Open Access This article is licensed under a Creative Commons Attribution 4.0 International License, which permits use, sharing, adaptation, distribution and reproduction in any medium or format, as long as you give appropriate credit to the original author(s) and the source, provide a link to the Creative Commons licence, and indicate if changes were made. The images or other third party material in this article are included in the article's Creative Commons licence, unless indicated otherwise in a credit line to the material. If material is not included in the article's Creative Commons licence and your intended use is not permitted by statutory regulation or exceeds the permitted use, you will need to obtain permission directly from the copyright holder. To view a copy of this licence, visit http://creativecommons.org/licenses/by/4.0/ The Creative Commons Public Domain Dedication waiver (http://creativecommons.org/publicdomain/zero/1.0/) applies to the data made available in this article, unless otherwise stated in a credit line to the data. 
(Continued from previous page)

Conclusions: The prevalence of new tobacco-alternative products is growing in popularity among Japanese adolescents. Dual use is common, and many adolescents use new products only. Moreover, e-cigarettes might attract a broader range of groups to smoking. Continuous monitoring and research are needed to investigate their influence as a possible gateway to tobacco smoking.

Keywords: Cigarette smoking, E-cigarettes, Tobacco use, Adolescents, Smoking, Heat-not-burn tobacco, Prevalence

\section{Background}

Smoking is a preventable health risk factor that results in numerous diseases and deaths [1,2]. Smoking control is particularly critical among adolescents, as individuals who use tobacco at a young age are at a considerably higher risk of becoming subsequent smokers [3]. Moreover, tobacco can be a gateway to other types of drug dependence [4]. Therefore, smoking control during adolescence is a crucial public health issue. The National Health Promotion Act has focused on tobacco control, and the prevalence of adolescents who report having smoked combustible cigarettes within last 30 days has continued to decline from 2000 to 2014; 9.4/5.6\% (boys/ girls) to $1.3 / 0.6 \%$ in junior high school students and $29.9 / 13.1 \%$ to $3.5 / 1.5 \%$ in high school students [5]. However, in recent years, tobacco industries have begun selling new tobacco-related products such as electronic cigarettes (e-cigarettes) and heat-not-burn (HNB) tobacco as alternatives to combustible cigarettes [6].

E-cigarettes use a battery to heat a cartridge containing a liquid, generating steam (i.e. smoke from burning is not generated) [7, 8]. E-cigarettes were first launched in China in 2003, and their consumption has shown a global growth through intense promotion via media geared towards young people, such as YouTube $[9,10]$. In smoking surveys worldwide, a rapid rise in the use of e-cigarettes has been seen among adults and adolescents [11-13]. Some of the purported benefits of e-cigarettes are that fewer harmful substances are generated compared to combustible cigarettes $[14,15]$ and that they can lead to the reduction or cessation of combustible cigarette use. However, there is a concern, particularly for adolescents, that the use of e-cigarettes may cause an increase in established smokers in the future [16]. Moreover, the longitudinal health impact of e-cigarettes has not yet been sufficiently clarified [17]; thus, its use involves potential harm. In Japan, the emergence of ecigarettes was evaluated by the authorities, and the sale of e-cigarettes containing nicotine is prohibited by the Pharmaceutical Affairs Law of 2010. However, ecigarettes without nicotine are accessible to adolescents and youth because they are not covered by this law.

HNB tobacco, also known as the 'I-quit-ordinarysmoking' (IQOS) system, involves an electronic device that heats tobacco leaves in a stick, and the user inhales the generated aerosol instead of smoke [18]. Tobacco companies in Japan are promoting HNB tobacco as a cigarette that causes less harm to users and bystanders. Philip Morris International (PMI) petitioned the US Food and Drug Administration for approval of HNB tobacco products as a smoking cessation tool, but the application was declined. In 2014, PMI introduced IQOS only in Japan and Italy and was available in 37 countries by $\mathrm{Au}-$ gust 2018. Japan is the unique country in which HNB tobacco was legally sold nationwide under the Tobacco Industries Act, making it an important market for companies that produce HNB products [19]. The popularity and use of HNB tobacco have increased [20]; in October 2016, Japan comprised $98 \%$ of the worldwide IQOS sales [21]. Other HNB products include Japan Tobacco's Ploom TECH (2016) and British American Tobacco's Glo product line (2016). Thus, tobacco companies are looking to expand their market offerings [22].

In Japan, where there is a unique market for tobaccorelated products, reports on the prevalence of e-cigarette and HNB tobacco use are limited to Internet surveys targeting individuals aged over 18 [23]. As the rapid increase in the popularity of e-cigarettes among adolescents in other countries and of HNB tobacco use in Japan, investigating the prevalence of new products among adolescents is important. Thus, from the 2017 Lifestyle Survey of Adolescents, we obtained data on junior high and high school students' smoking habits and their use of the new types of tobacco-related products in Japan. Our study aimed to clarify the prevalence of smoking of combustible cigarettes and new tobacco products, as well as the combined use of these products and to compare the background of adolescent users of different types of products.

\section{Methods \\ Study population}

This study aimed to evaluate the nationwide prevalence of use of cigarettes and alternative tobacco products. Considering sampling bias, this study involved a crosssectional random sample survey with single-stage cluster sampling [24], wherein the school was set as the cluster unit. Using the national school directory, junior high schools attended by students aged 12 to 15 and high schools, attended by students aged 15 to 18, throughout Japan were randomly selected, and the survey was 
distributed to all students in these schools in 2017. A total of 98 of Japan's 10,325 junior high schools and 86 of the 4907 high schools were sampled. The proportion of private schools was $8.2 \%$ of junior high schools and $19.8 \%$ of high schools. The survey period was from December 2017 to February 2018.

\section{Data collection}

We asked the school principals for cooperation and sent the survey forms to them for distribution to students through class teachers, who explained to the students that participation was voluntary and that they should answer honestly. The students were given anonymous questionnaires and envelopes, which were completed and sealed by the students, collected by their teachers, and then returned to our research office with the seals intact. This survey was approved by the Ethics Review Committee of Tottori University Faculty of Medicine.

\section{Measures}

The questionnaire survey focused on adolescents' lifestyle, such as smoking behaviour, alcohol use, and school life (Additional File 1). Referring to the questionnaires used by Centers of Disease Control and Prevention and WHO $[25,26]$, the questions about smoking included experience with and frequency of combustible cigarette smoking: 'Have you ever smoked a combustible cigarette including even a single puff?' and 'How many days have you smoked combustible cigarettes in the previous 30 days?'. Similar questions were used for new tobaccoalternative products. Ever users, current users, and daily users were defined as those who had smoked even once in the past, had smoked at least once in the past 30 days, and had smoked every day for the past 30 days, respectively. These definitions of frequency were also used for users of e-cigarettes and HNB tobacco.

\section{Tobacco products}

Since we needed to discriminate between combustible cigarettes and new tobacco-alternative products, in the questionnaire, we described a combustible cigarette as 'a cigarette made from rolled paper and tobacco and smoked with fire'. Due to the number of e-cigarette brands currently for sale, we used the names of the most popular brands in the questionnaire, stating 'electronic cigarettes include brands such as フレヴオ (FLEVO), エミリ (EMILI), ビタフル(VITAFUL), and ビタシグ (VITASIG)'. The question for HNB tobacco also included product names to avoid any confusion: 'heat-not-burn tobacco is any product such as アイコス (IQOS), プルームテック (Plume Tech), or グロー (glo)'.

\section{Data analysis}

The age-adjusted prevalence rates were calculated using the number of junior high and high school students nationwide from the School Basic Survey of the Ministry of Education, Science and Technology (2017) as a standard population. Proportions with a $95 \%$ confidence interval (95\% CI), as presented in the tables, were calculated using a weighting method based on one-stage cluster random sampling [24]. Two proportion $Z$-tests were conducted to compare the prevalence of each product between boys and girls. To observe the associations between the use of the three different types of products, we calculated the prevalence of combined use. Then, the proportions of combined use of products were calculated, which made the comparison of combined use easier. Moreover, the background of ever users of different products was compared in terms of gender, school grade, municipality size, having breakfast, and participating in club activities. IBM SPSS 25.0 was used for all data analyses.

\section{Results}

A total of $56 \%$ of 184 schools, including 48 of 98 junior high schools (response rate: 49\%) and 55 of 86 high schools (response rate: 64\%) took part in the survey. In total, 64,417 questionnaires were returned to the research office. After excluding the questionnaires that were blank, or had invalid/missing gender information or inconsistent responses, 64,152 questionnaires were analysed. The characteristics of the study participants are shown in Table 1. The mean age (standard deviation) of students in junior high school was 13.7 (1.0) years, and $16.7(0.9)$ years for high school students. For the gender-ratio, $50.3 \%$ of junior high school students and $55.8 \%$ of high school students were boys.

\section{Rates of cigarette and new tobacco-alternative product use}

Broken down by product type and student gender, the age-adjusted rate of students who were ever/current/ every day users of cigarettes, e-cigarettes, or HNB tobacco are shown in Table 2.

The rate of ever users of cigarettes (male/female/both) was $3.1 \%$ (95\% CI: $3.0,3.2) / 2.1 \%$ (95\% CI: $2.0,2.2) / 2.6 \%$ (95\% CI: 2.5, 2.7) for junior high school students, and 6.9\% (95\% CI: 6.6, 7.2)/3.3\% (95\% CI: 2.0, 2.2)/5.1\% (95\% CI: $2.3,2.9)$ for high school students. E-cigarette use was slightly lower than cigarette use, at $2.4 \%$ (95\% CI: 2.3 , 2.5)/1.7\% (95\% CI: $1.6,1.8) / 2.1 \%$ (95\% CI: $2.0,2.2$ ) among junior high school students, and $4.9 \%$ (95\% CI: 4.7, 5.1)/2.1\% (95\% CI: $2.1,2.1) / 3.5 \%$ (95\% CI: 3.3, 3.7) among high school students. The rate of HNB tobacco users was relatively lower relative to other products, at 1.3\% (95\% CI: 1.3, 1.3)/0.9\% (95\% CI: 0.9, 0.9)/1.1\% (95\% 
Table 1 Baseline characteristics of the study participants

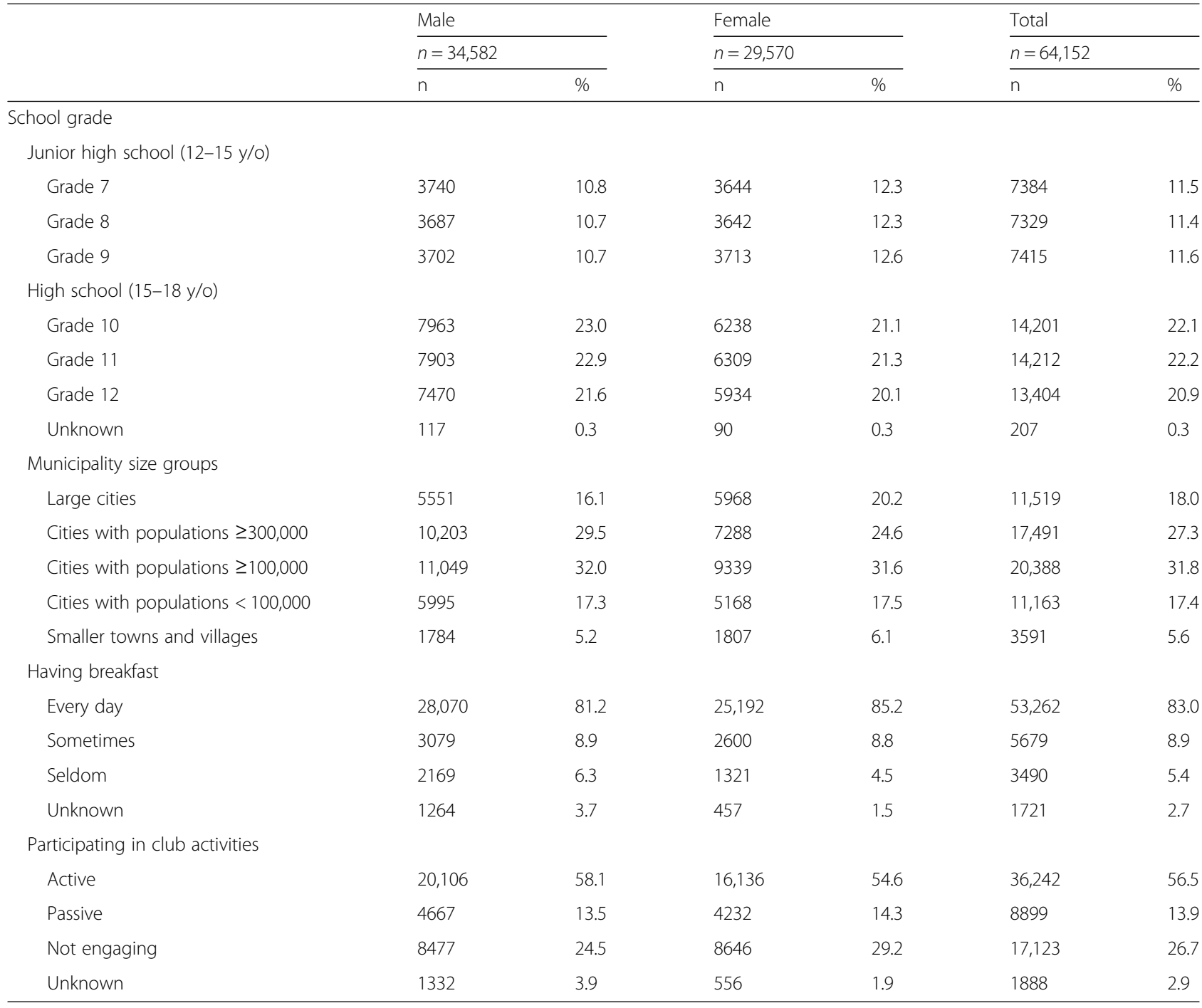

CI: 1.0, 1.2) among junior high school students, and 2.9\% (95\% CI: 2.8, 3.0)/1.4\% (95\% CI: 1.4, 1.4)/2.2\% (95\% CI: 2.0, 2.4) among high school students. Experience with of all products was significantly higher among adolescent boys than girls.

The rate of current use of the three products (male/female/both) was rare. For cigarettes, the rate was $0.7 \%$ (95\% CI: 0.7, 0.7)/0.5\% (95\% CI: 0.5, 0.5)/0.6\% (95\% CI: $0.5,0.7$ ) among junior high school students, and $2.0 \%$ (95\% CI: 1.9, 2.1)/0.9\% (95\% CI: 0.9, 0.9)/1.5\% (95\% CI: $1.4,1.6)$ among high school students. For e-cigarettes, it was $0.8 \%$ (95\% CI: 0.8, 0.8)/0.5\% (95\% CI: 0.5, 0.5)/0.7\% (95\% CI: $0.6,0.8)$ for junior high school students, and 1.5\% (95\% CI: 1.4, 1.6)/0.5\% (95\% CI: 0.5, 0.5)/1.0\% (95\% CI: $0.9,1.1)$ for high school students. For HNB tobacco, it was $0.6 \%$ (95\% CI: $0.6,0.6) / 0.4 \%$ (95\% CI: $0.3,0.5) /$ 0.5\% (95\% CI: $0.5,0.5)$ for junior high school students, and $1.2 \%$ (95\% CI: $1.1,1.3) / 0.6 \%$ (95\% CI: $0.6,0.6) / 0.9 \%$
(95\% CI: 0.8, 1.0) for high school students. Among high school students, current use of three products were significantly higher among boys than girls. Significant difference was observed only in e-cigarette use among junior high school students.

The proportion of students who used the products every day was quite low, with the highest prevalence being that of cigarette use among high school students (male/female/both): $0.7 \%$ (95\% CI: $0.6,0.8) / 0.2 \%$ (95\% CI: $0.2,0.2) / 0.5 \%$ (95\% CI: $0.4,0.6)$. The age-adjusted rates for the new products were $0.1 \%$ or less.

As shown in Fig. 1, the use of combustible cigarettes was the most prevalent regardless of grade level. Ever use of e-cigarettes followed slightly below that of cigarettes, especially among the younger generation. A divergence was evident between ever use of HNB tobacco and that of the two other types. As for current use, the graphs of the three products overlapped each other in 
Table 2 Junior high (grades 7-9) and high school (grades 1012) students' age-adjusted smoking prevalence rates by gender

\begin{tabular}{|c|c|c|c|c|c|c|}
\hline \multirow{3}{*}{ Grades 7-9 } & \multicolumn{2}{|c|}{ Ever C use } & \multicolumn{2}{|c|}{ Ever EC use } & \multicolumn{2}{|c|}{ Ever HNB use } \\
\hline & \multirow[t]{2}{*}{$\%$} & \multirow[t]{2}{*}{$95 \% \mathrm{Cl}$} & \multirow[t]{2}{*}{$\%$} & \multirow[t]{2}{*}{$95 \% \mathrm{Cl}$} & \multirow[t]{2}{*}{$\%$} & \multirow[t]{2}{*}{$95 \%$ C } \\
\hline & & & & & & \\
\hline Male & 3.1 & $3.0,3.2$ & 2.4 & $2.3,2.5$ & 1.3 & $1.3,1.3$ \\
\hline Female & $2.1^{* *}$ & $2.0,2.2$ & $1.7^{* *}$ & $1.6,1.8$ & $0.9^{*}$ & $0.9,0.9$ \\
\hline Both & 2.6 & $2.5,2.7$ & 2.1 & $2.0,2.2$ & 1.1 & $1.0,1.2$ \\
\hline \multicolumn{7}{|c|}{ Grades 10-12 } \\
\hline Male & 6.9 & $6.6,7.2$ & 4.9 & $4.7,5.1$ & 2.9 & $2.8,3.0$ \\
\hline Female & $3.3^{* *}$ & $3.2,3.4$ & $2.1^{* *}$ & $2.1,2.1$ & $1.4^{* *}$ & $1.4,1.4$ \\
\hline \multirow[t]{3}{*}{ Both } & 5.1 & $4.8,5.4$ & 3.5 & $3.3,3.7$ & 2.2 & $2.0,2.4$ \\
\hline & \multicolumn{2}{|c|}{ Current $C$ use } & \multicolumn{2}{|c|}{ Current EC use } & \multicolumn{2}{|c|}{ Current HNB use } \\
\hline & $\%$ & $95 \% \mathrm{Cl}$ & $\%$ & $95 \% \mathrm{Cl}$ & $\%$ & $95 \% \mathrm{Cl}$ \\
\hline \multicolumn{7}{|l|}{ Grades 7-9 } \\
\hline Male & 0.7 & $0.7,0.7$ & 0.8 & $0.8,0.8$ & 0.6 & $0.6,0.6$ \\
\hline Female & 0.5 & $0.5,0.5$ & $0.5^{* *}$ & $0.5,0.5$ & 0.4 & $0.4,0.4$ \\
\hline Both & 0.6 & $0.5,0.7$ & 0.7 & $0.6,0.8$ & 0.5 & $0.5,0.5$ \\
\hline \multicolumn{7}{|c|}{ Grades 10-12 } \\
\hline Male & 2.0 & $1.9,2.1$ & 1.5 & $1.4,1.6$ & 1.2 & $1.1,1.3$ \\
\hline Female & $0.9^{* *}$ & $0.9,0.9$ & $0.5^{* *}$ & $0.5,0.5$ & $0.6^{* *}$ & $0.6,0.6$ \\
\hline \multirow[t]{3}{*}{ Both } & 1.5 & $1.4,1.6$ & 1.0 & $0.9,1.1$ & 0.9 & $0.8,1.0$ \\
\hline & \multicolumn{2}{|c|}{ Daily C use } & \multicolumn{2}{|c|}{ Daily EC use } & \multicolumn{2}{|c|}{ Daily HNB use } \\
\hline & $\%$ & $95 \% \mathrm{Cl}$ & $\%$ & $95 \% \mathrm{Cl}$ & $\%$ & $95 \% \mathrm{Cl}$ \\
\hline \multicolumn{7}{|l|}{ Grades 7-9 } \\
\hline Male & 0.2 & $0.2,0.2$ & 0.1 & $0.1,0.1$ & 0.1 & $0.1,0.1$ \\
\hline Female & 0.1 & $0.1,0.1$ & 0.1 & $0.1,0.1$ & 0.1 & $0.1,0.1$ \\
\hline Both & 0.1 & $0.1,0.1$ & 0.1 & $0.1,0.1$ & 0.1 & $0.0,0.2$ \\
\hline \multicolumn{7}{|c|}{ Grades 10-12 } \\
\hline Male & 0.7 & $0.6,0.8$ & 0.1 & $0.1,0.1$ & 0.1 & $0.1,0.1$ \\
\hline Female & $0.2^{* *}$ & $0.2,0.2$ & 0.1 & $0.1,0.1$ & $0.0^{* *}$ & $0.0,0.0$ \\
\hline Both & 0.5 & $0.4,0.6$ & 0.1 & $0.1,0.1$ & 0.1 & $0.1,0.1$ \\
\hline
\end{tabular}

$\mathrm{C}$ combustible cigarette, EC electronic cigarette, $H N B$ heat-not-burn tobacco, $\mathrm{Cl}$ confidence interval

Two proportion Z-tests were conducted to compare male and female. ${ }^{* *} P<0.01,{ }^{*} P<0.05$

the younger generation, but in grades 11 and 12, combustible cigarette use was significantly higher than the use of the other two products.

\section{Combined use of any tobacco product}

The age-adjusted rates of combined use of tobaccorelated products were calculated (Additional File 2), including all possible combinations of combustible cigarettes, e-cigarettes, and HNB tobacco. Across the various patterns, the exclusive users of cigarettes and exclusive users of e-cigarettes were the largest groups.

Moreover, to make comparisons more understandable, the proportions of ever and current users of any product are shown in Table 3. In terms of ever use, the proportion of exclusive users of combustible cigarettes was about $40 \%$ of users of any product in both junior high schools and high schools. Meanwhile, around 36\% of users of any product used only e-cigarettes and/or HNB tobacco in junior high schools. Among high school users, around $25 \%$ of males and $32 \%$ of females ever used either one or both new alternative products. Furthermore, among junior high school students who currently used any product, exclusive e-cigarette users were the largest group among all patterns of use. In high school, exclusive combustible cigarette use, 30\%, was dominant across the patterns; however, more than $30 \%$ of users currently used only new alternative products. It is worth mentioning that dual users who currently used both cigarettes and another type of products exceeded $30 \%$ in junior high school as well as in high school.

Additional File 3 shows the comparison of ever users of different products according to gender, school grade, municipality size, custom of having breakfast, and participation in club activities. Across the different users, the proportions of males were higher than those of females. However, gender differences were smaller when comparing e-cigarette users and HNB users with cigarette users. There were upward trends from lower to higher school grades in exclusive cigarette use and cigarette use combined with other products, but the trends were not clear among new alternative products users. Regarding lifestyle, adolescents who ever used new types of products showed acceptable habits. The percentage of individuals who had breakfast every day and participated in club activities was higher among new products users than among cigarette users.

\section{Discussion}

This study is the first in Japan to examine the prevalence of use of combustible cigarettes and new tobaccoalternative products among adolescents. At present, the rate of combustible cigarette use was the highest, followed by e-cigarettes and HNB tobacco use. The rates of use for all three products rose in tandem with increasing school grade. The prevalence of combustible cigarette use was much higher relative to alternative products among high school students, as these alternative products had been introduced into the market more recently. However, ever use of e-cigarettes became close to that of combustible cigarettes among the younger generations. Moreover, the current use of the three products was quite similar, suggesting that new tobaccoalternative products are becoming popular among young users.

Japan is included in the countries with the lowest smoking prevalence according to a World Health Organization report on the global tobacco epidemic 


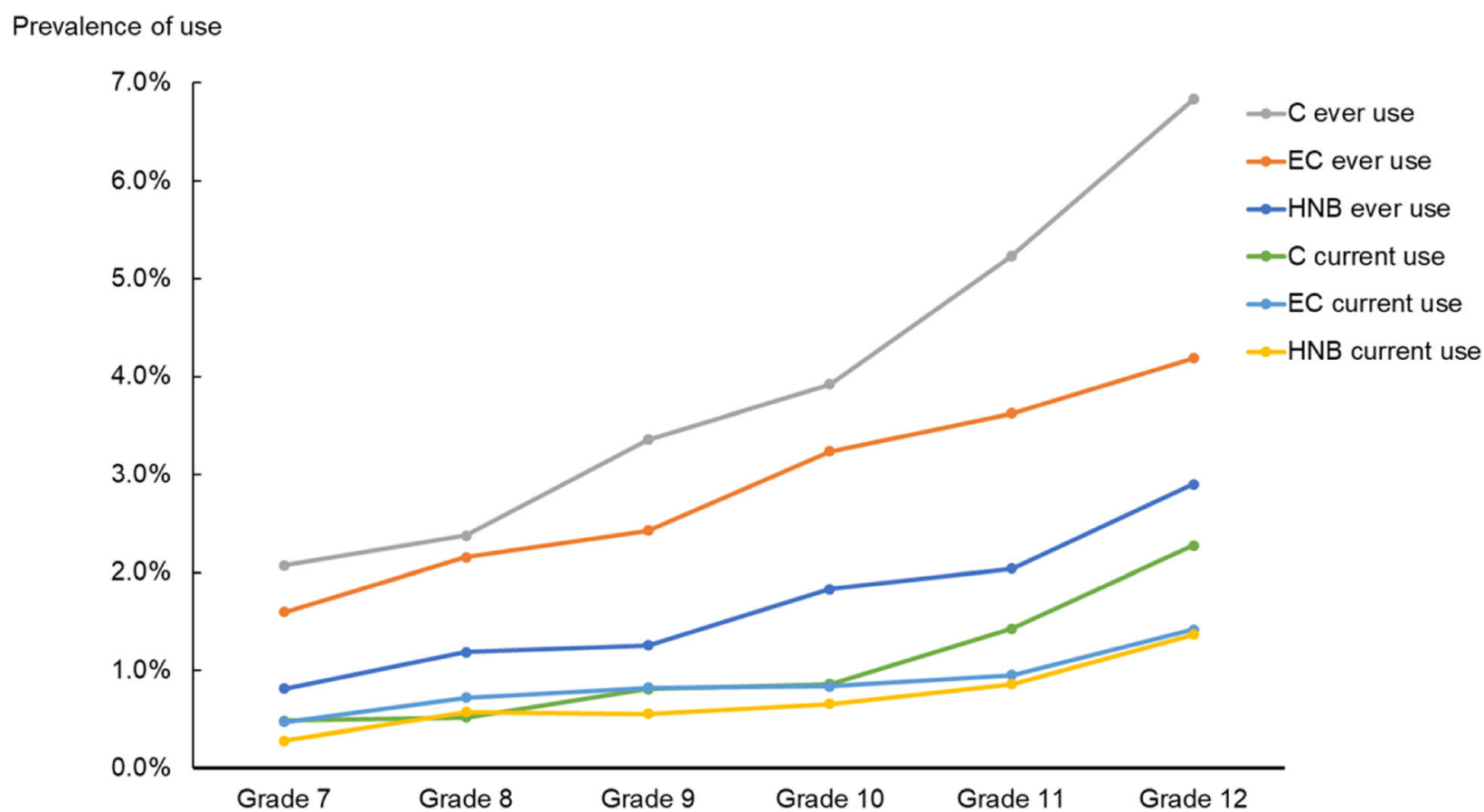

Fig. 1 Prevalence of the three tobacco-related products in each grade (both genders). C: combustible cigarette, EC: electronic cigarette, HNB: heat-not-burn tobacco

Table 3 Junior high (grades 7-9) and high school (grades 1012) students' age-adjusted prevalence of combined smoking by gender

\begin{tabular}{|c|c|c|c|c|c|c|c|}
\hline \multicolumn{8}{|c|}{ Proportions of students who ever used either } \\
\hline \multirow[b]{2}{*}{ C } & \multirow[b]{2}{*}{ HNB } & \multicolumn{3}{|c|}{ Grades 7-9, ever use (\%) } & \multicolumn{3}{|c|}{ Grades 10-12, ever use (\%) } \\
\hline & & Male & Female & Both & Male & Female & Both \\
\hline+- & - & 41.1 & 40.3 & 40.8 & 38.4 & 43.2 & 39.8 \\
\hline++ & - & 7.8 & 6.5 & 7.3 & 11.6 & 6.0 & 10.0 \\
\hline+- & + & 5.6 & 4.4 & 5.1 & 8.1 & 7.9 & 8.0 \\
\hline++ & + & 9.6 & 12.3 & 10.7 & 16.7 & 10.2 & 14.8 \\
\hline+ & - & 26.3 & 27.5 & 26.8 & 20.0 & 23.6 & 21.1 \\
\hline - - & + & 5.0 & 4.4 & 4.7 & 2.7 & 5.5 & 3.5 \\
\hline$-\quad+$ & + & 4.6 & 4.6 & 4.6 & 2.4 & 3.5 & 2.7 \\
\hline
\end{tabular}

Proportions of students who currently used either
Grades 7-9, current use (\%)

C EC HNB Male

$+\quad-23.3$

$++\quad 4.6 \quad 3.2$

$+\quad+\quad 4.79 .9$

$++\quad 18.7 \quad 28.5$

- +31.328 .6$

- + 10.07 .7

- + 7.3

1.1
Grades 10-12, current use (\%)

$\begin{array}{llll}\text { Both } & \text { Male } & \text { Female } & \text { Both } \\ 22.4 & 30.7 & 29.9 & 30.5 \\ 4.1 & 6.8 & 6.6 & 6.8 \\ 6.6 & 13.7 & 17.4 & 14.6 \\ 22.4 & 16.0 & 14.6 & 15.7 \\ 30.3 & 21.3 & 16.0 & 20.0 \\ 9.1 & 6.5 & 9.5 & 7.3 \\ 5.0 & 4.9 & 6.0 & 5.1\end{array}$

[27]. The present study focused on the use of new tobacco-alternative products among Japanese adolescents. However, even considering the increasing prevalence of these new products, the smoking rate has shown a downward trend compared with the respective proportions in time-series data. The current use of ecigarettes of $0.7 \%$ in junior high schools and $1.0 \%$ in high schools in Japan is lower than that reported by the 2017 National Youth Tobacco Survey in the US (3.3\% in middle school and $11.7 \%$ in high school) [28]. The law that regulates the sale of e-cigarettes containing nicotine in Japan might contribute to the lower use of these products. Another explanation may be that HNB tobacco exists as a substitute for e-cigarettes. Even though the current use of new products was low in our study, the use of e-cigarettes has been increasing in several countries. Continuous monitoring of e-cigarette use is thus indispensable.

Moreover, given the large population of e-cigarettes among any products users, it is of significance in assessing whether e-cigarettes used by Japanese adolescents contain nicotine or not. A previous study among Canadian high school students by Hamilton et al. showed that approximately $72 \%$ of those adolescents who were ever e-cigarettes users used non-nicotine e-cigarettes, while about 28\% used nicotine e-cigarettes [29]. Similarly, a previous study indicated that in Japan, about 30\% of ever users of new tobacco products used e-cigarettes containing nicotine [19]. The regulation of e-cigarettes in 
Canada is quite similar to that in Japan, suggesting that the figures among the Japanese adolescents might be comparable to Hamilton's results. To note, Tabuchi et al. indicated that about $15 \%$ of those who were ever users had used e-cigarettes with unknown nicotine. Misinformation about nicotine content is concerning because nicotine might impact the developing brain of adolescents [29]. Future research should investigate these issues.

The prevalence of HNB tobacco use was lower than that of e-cigarette use; however, HNB tobacco use was still observed among adolescents. To our knowledge, there are no comparable reports about HNB tobacco use in other countries. Tabuchi et al. reported the current use as $3.6 \%$ in a 2017 internet survey targeting adults in Japan [23], which is comparable to our results. The prevalence of HNB tobacco use is more similar between adolescents and adults relative to the prevalence of combustible cigarette use. Awareness of and advertisements for HNB tobacco have increased in recent years [22]; a domestic Japanese newspaper reported in 2018 that the sales units of HNB tobacco exceeded 2 million for Glo, 5 million for IQOS, and 4 million for Ploom Tech, and indicated that the tobacco market was accelerating the shift to HNB tobacco [30]. The association between smoking rates and tobacco advertisements has been previously studied, and the increase in the use of ecigarettes in Western countries has been attributed to media promotion [31]. The current momentum of HNB tobacco in Japan is expected to affect its future use rates. Its prevalence should be monitored, as there is substantial uncertainty regarding the health consequences of HNB tobacco [32, 33].

Gender differences in the prevalence rates were examined in the current study. Boys were more likely to use the tobacco-related products, which is consistent with the results previously reported by the WHO [27] and another study conducted in Japan $[19,23]$. Previous research has indicated the importance of investigating gender difference in e-cigarette marketing strategies including innovations in product features (e.g., packaging and device design, appealing flavours), as they can influence gender difference in consumption. The authors also highlighted the necessity of examining gender differences in nicotine use by quantifying the amount of nicotine in the e-cigarettes being used by youth [34]. To our knowledge, no research to date has investigated gender difference in HNB consumption. Future research should examine the context in which gender differences in nicotine use might occur.

This study also examined the various patterns of use of the three products. As for adolescents' ever use and current use, exclusive cigarette use was dominant in all cases except for the exclusive use of e-cigarettes in junior high school. A considerable proportion of anyproduct users were ever or current users of new alternative products only. Therefore, it is an important concern whether e-cigarette or HNB tobacco use can lead to established cigarette use in the future. A previous systematic review indicated that the use of e-cigarettes among adolescents was likely to cause subsequent cigarette smoking [16]. Although it is unclear, it is plausible that the use of HNB tobacco use has the same consequences. Future research is required to clarify this issue.

Another concern is 'dual use' which refers to the use of both combustible cigarette and at least one new tobacco products. Our results suggest that the proportion of dual users exceeded $30 \%$ in junior high school as well as in high school. Although the latest expert consensus indicated that e-cigarette use is much less harmful than smoking combustible cigarettes [17], dual use potentially denotes the addition of unknown harm from e-cigarettes or HNB tobacco to that of smoke from combustible cigarettes [17]. There is controversy over whether dual use of e-cigarettes can assist with smoking cessation or not. A recent systematic review has indicated that ecigarettes are not likely to lead to smoking cessation [16]. Furthermore, to date, there has been no empirical evidence that has indicated that HNB tobacco products play a role in cessation. Future research should investigate these issues in order to clarify their implications for the overall health impact of e-cigarettes and HNB tobacco in Japan.

Moreover, our results indicated different characteristics in the healthy behaviours between those who were cigarette users and new products users. Previous studies have suggested that smoking is associated with an unhealthy lifestyle $[35,36]$. Similarly, an association between health risk behaviour and e-cigarettes use has been reported [37]. However, to our knowledge, the relationship between new products and healthy behaviour among adolescents has not been sufficiently investigated. Dunbar et al. concluded that e-cigarettes use among adolescents is not necessarily associated with greater engagement in health behaviours compared to cigarette use [37]. With regard to HNB tobacco, Lee et al. indicated that physically active adolescents were more likely to use cigarettes as well as new products [38] and theorised that these findings were owing to peer influences from participating social activities. However, our results suggest that new products may be an entrance to smoking for a broad variety of adolescents, who are less likely to begin smoking if using combustible cigarettes alone. Previous studies indicated that new products might entice new groups of consumers with characteristics distinct from those of combustible cigarette smokers $[39,40]$. Although the mechanism has not been 
sufficiently clarified, it could be that new adolescent users may believe that the new products are 'safe' [41]. Future studies are needed to examine the association between health behaviours and the type of products used by adolescents. It is also significant to clarify whether young people who are at low-risk of becoming smokers are more attracted by new products.

A strength of the present study is that our large student sample represents the nationwide adolescent population of Japan. In addition, considering our specific tobacco regulation, Japan is a fertile market for tobacco industries. Our study is unique in that it reports on a novel product, HNB tobacco, which is not available in all countries. However, in this survey, the number of schools selected was relatively smaller than in past studies. Additionally, the response rates in junior high schools were low, leading to the use of age-adjusted rates in the tables. This study required strict ethical considerations due to the age groups taking part, which may have contributed to the low response rate. Although we devised questions about e-cigarettes and HNB tobacco, including the trade names of popular products, students still may not have recognised these products correctly and could have confused e-cigarettes and HNB tobacco. It is also difficult to confirm the validity of self-report answers. Continuous monitoring using the same standards and methods may be the only feasible option. Furthermore, this study entailed a cross-sectional analysis; therefore, the temporal relationship of how the smokers' practices changed as a consequence of the emergence of new tobacco products could not be clarified. Future research should address these limitations.

\section{Conclusions}

According to this nationwide population survey, the prevalence of new tobacco-related products is just below the use of combustible tobacco among Japanese adolescents. Dual use is common, and e-cigarettes or HNB tobacco use represent a considerable proportion of the tobacco-related products used by youth. Findings from background comparison suggest that new tobacco-related products might lure a broader population into smoking. The longitudinal impact of these new products remains unclear; thus, continuous monitoring and further research are necessary to provide guidance for the implementation of enhanced public measures against smoking and the use of new tobacco-related products.

\section{Supplementary information}

Supplementary information accompanies this paper at https://doi.org/10. 1186/s12889-020-08916-x.

Additional file 1. The list of questions from the survey questionnaire
Additional file 2. Junior high (grades 7-9) and high school (grades 1012) students' age-adjusted combined smoking prevalence rates by gender.

Additional file 3. Patterns of ever use of tobacco-related products by demographics, lifestyle, and future education intention.

\section{Abbreviations}

E-cigarette: Electronic cigarette; HNB: Heat-not-burn; Cl: Confidence interval; WHO: World Health Organization

\section{Acknowledgements}

We would like to thank Editage (www.editage.jp) for English language editing.

\section{Authors' contributions}

$\mathrm{YO}, \mathrm{SH}$, and YoK designed the study and devised the study protocols. OI, $\mathrm{YuO}, \mathrm{MJ}$, and $\mathrm{HY}$ did the literature review and helped summarise previous research studies. HK, AK, MF, and Al carried out the statistical analyses. YK wrote the first draft of the manuscript. All authors have read and approved the manuscript.

\section{Funding}

This study was supported by a grant for Comprehensive Research on Lifestyle-Related Diseases including Cardiovascular Diseases and Diabetes Mellitus by the Ministry of Health and Welfare Health Science Research Fund in Japan (grant no. 29060801). The funding body did not have any role in the design of the study; collection, analysis, and interpretation of data; or in writing the manuscript.

\section{Availability of data and materials}

The datasets used in the current study are available from the corresponding author on reasonable request.

\section{Ethics approval and consent to participate}

The participants were older than 12 years of age. Before the survey, the school principals provided participants' parents with the details of the survey. The parents were advised that they were allowed to refuse participation if they were reluctant to allow their children to take part in the survey. In other words, the parents were given the opportunity to opt their children out of the survey if they were not comfortable with them participating in the survey. The students whose parents refused permission for the survey were not included. This survey and opt out parental consent procedure were approved by the Ethics Review Committee of Tottori University Faculty of Medicine (reference no. 17A078)

\section{Consent for publication}

Not applicable.

\section{Competing interests}

The authors declare that they have no competing interests.

\section{Author details}

'Division of Environmental and Preventive Medicine, Department of Social Medicine, Faculty of Medicine, Tottori University, Nishi-machi 86, Yonago-shi, Tottori 683-8503, Japan. ${ }^{2}$ Department of Public Health, School of Medicine, Nihon University, Itabashi-ku, Tokyo, Japan. ${ }^{3}$ National Institute of Alcoholism, Kurihama National Hospital, Yokosuka, Kanagawa, Japan. ${ }^{4}$ Primary Care and Medical Education, Graduate School of Comprehensive Human Sciences, Majors of Medical Science, University of Tsukuba, Tsukuba, Ibaraki, Japan. ${ }^{5}$ Department of Public Health, Okayama University Graduate School of Medicine, Dentistry and Pharmaceutical Sciences, Okayama-shi, Okayama, Japan.

Received: 14 October 2019 Accepted: 13 May 2020

Published online: 20 May 2020

References

1. Forouzanfar MH, Alexander L, Anderson HR, Bachman VF, Biryukov S, Brauer $\mathrm{M}$, et al. Global, regional, and national comparative risk assessment of 79 behavioural, environmental and occupational, and metabolic risks or 
clusters of risks in 188 countries, 1990-2013: a systematic analysis for the global burden of disease study 2013. Lancet. 2015;386(10010):2287-323.

2. World Health Organization. Tobacco fact sheet. 2019. https:/www.who.int/ news-room/fact-sheets/detail/tobacco. Accessed 11 February 2019.

3. Mathers M, Toumbourou JW, Catalano RF, Williams J, Patton GC. Consequences of youth tobacco use: a review of prospective behavioural studies. Addiction. 2006;101(7):948-58. https://doi.org/10.1111/j.1360-0443. 2006.01438.x.

4. World Health Organization. Health effects of smoking among young people. https://www.who.int/tobacco/control/populations/youth_health_effects/en/. Accessed 8 July 2019.

5. Ministry of Health Lab. The latest tobacco information. 2018. http://www. health- net.or.jp/tobacco/product/pd100000.html. Accessed 8 July 2019.

6. Mejia $A B$, Ling PM. Tobacco industry consumer research on smokeless tobacco users and product development. Am J Public Health. 2010;100(1): 78-87. https://doi.org/10.2105/AJPH.2008.152603.

7. Cobb NK, Byron MJ, Abrams DB, Shields PG. Novel nicotine delivery systems and public health: the rise of the "e-cigarette". Am J Public Health. 2010; 100(12):2340-2. https://doi.org/10.2105/A.JPH.2010.199281.

8. Eriksen M, Mackay J, Ross H. The Tobacco Atlas. 4th ed. Atlanta: American Cancer Society: World Lung Foundation; 2012

9. Yamin CK, Bitton A, Bates DW. E-cigarettes: a rapidly growing Internet phenomenon. Ann Intern Med. 2010;153(9):607-609. doi: 10.1.1.691.747.

10. Hua M, Yip H, Talbot P. Mining data on usage of electronic nicotine delivery systems (ENDS) from YouTube videos. Tob Control. 2013;22(2):103-6. https://doi.org/10.1136/tobaccocontrol-2011-050226.

11. Carroll Chapman SL, Wu LT. E-cigarette prevalence and correlates of use among adolescents versus adults: a review and comparison. J Psychiatr Res. 2014;54:43-54. https://doi.org/10.1016/j.jpsychires.2014.03.005.

12. Pepper JK, Brewer NT. Electronic nicotine delivery system (electronic cigarette) awareness, use, reactions and beliefs: a systematic review. Tob Control. 2014;23(5):375-84. https://doi.org/10.1136/tobaccocontrol-2013051122.

13. Dutra LM, Glantz SA. High international electronic cigarette use among never smoker adolescents. J Adolesc Health. 2014;55(5):595-7. https://doi. org/10.1016/j.jadohealth.2014.08.010.

14. Goniewicz ML, Knysak J, Gawron M, Kosmider L, Sobczak A, Kurek J, et al. Levels of selected carcinogens and toxicants in vapour from electronic cigarettes. Tob Control. 2014;23(2):133-9. https://doi.org/10.1136/ tobaccocontrol-2012-050859

15. Cahn Z, Siegel M. Electronic cigarettes as a harm reduction strategy for tobacco control: a step forward or a repeat of past mistakes? J Public Health Policy. 2011;32(1):16-31. https://doi.org/10.1057/jphp.2010.41.

16. Soneji S, Barrington-Trimis JL, Wills TA, Leventhal AM, Unger JB, Gibson LA, et al. Association between initial use of e-cigarettes and subsequent cigarette smoking among adolescents and young adults: a systematic review and meta-analysis. JAMA Pediatr. 2017;171(8):788-97. https://doi.org/ 10.1001/jamapediatrics.2017.1488

17. National Academies of Sciences, Engineering, and Medicine. Public Health Consequences of E-Cigarettes. Washington, DC: National Academies Press; 2018.

18. Farsalinos KE, Yannovits N, Sarri T, et al. Nicotine delivery to the aerosol of a heat-not-burn tobacco product: comparison with a tobacco cigarette and e-cigarettes. Nicotine Tob Res. 2018;20(8):1004-9. https://doi.org/10.1093/ $n$ tr/ntx138.

19. Tabuchi T, Kiyohara K, Hoshino T, Bekki K, Inaba Y, Kunugita N. Awareness and use of electronic cigarettes and heat-not-burn tobacco products in Japan. Addiction. 2016;111(4):706-13. https://doi.org/10.1111/add.13231.

20. Caputi TL, Leas E, Dredze M, Cohen JE, Ayers JW. They're heating up: internet search query trends reveal significant public interest in heat-notburn tobacco products. PLoS One. 2017;12(10):e0185735. https://doi.org/10. 1371/journal.pone.0185735.

21. Miyazaki Y, Tabuchi T. Educational gradients in the use of electronic cigarettes and heat-not-burn tobacco products in Japan. PLoS One. 2018; 13(1):e0191008. https://doi.org/10.1371/journal.pone.0191008.

22. Caputi TL. Industry watch: heat-not-burn tobacco products are about to reach their boiling point. Tob Control. 2017;26(5):609-10. https://doi.org/10. 1136/tobaccocontrol-2016-053264.

23. Tabuchi T, Gallus S, Shinozaki T, Nakaya T, Kunugita N, Colwell B. Heat-notburn tobacco product use in Japan: its prevalence, predictors and perceived symptoms from exposure to secondhand heat-not-burn tobacco aerosol.
Tob Control. 2018;27(e1):e25-33. https://doi.org/10.1136/tobaccocontrol2017-053947.

24. Cochran WG. Sampling Techniques. 3rd ed. New York: Wiley; 1977.

25. Centers for Disease Control and Prevention. Historical NYTS Data and Documentation. 2019 NYTS questionnaire. Secondary Historical NYTS Data and Documentation. 2019 NYTS questionnaire 2019. https://www.cdc.gov/tobacco/ data_statistics/surveys/nyts/data/index.html. Accessed 31 January 2020.

26. PAHO. Global Youth Tobacco Survey (GYTS). Secondary Global Youth Tobacco Survey (GYTS) 2019. https://www.paho.org/hq/index.php?option= com_content\&view=article\&id=13432: gyts\&ltemid=42359\&lang=en Accessed 31 January 2020.

27. World Health Organization. WHO Report on the Global Tobacco Epidemic Monitoring Tobacco Use and Prevention Policies. Geneva: World Health Organization; 2017. https://www.who.int/tobacco/global_report/2017/en/. Accessed 8 July, 2019.

28. Wang TW, Gentzke A, Sharapova S, Cullen KA, Ambrose BK, Jamal A. Tobacco Product Use Among Middle and High School Students - United States, 2011-2017. MMWR Morb Mortal Wkly Rep. 2018;67(22):629-33. https://doi.org/10.15585/mmwr.mm6722a3.

29. Hamilton HA, Ferrence R, Boak A, et al. Ever use of nicotine and nonnicotine electronic cigarettes among high school students in Ontario, Canada. Nicotine Tob Res. 2015;17(10):1212-8. https://doi.org/10.1093/ntr/ntu234.

30. Takashi H. Heat not burn tobacco market. 2018. https://www.sankei.com/ economy/news/180802/ecn1808020003-n1.html. Accessed 5 February 2019.

31. Nicolas M. Juuling adolescents: a new health concern. Lancet Child Adolesc Health. 2018;2(7):465. https://doi.org/10.1016/\$2352-4642(18)30182-2.

32. Auer R, Concha-Lozano N, Jacot-Sadowski I, Cornuz J, Berthet A. Heat-notburn tobacco cigarettes: smoke by any other name. JAMA Intern Med. 2017; 177(7):1050-2. https://doi.org/10.1001/jamainternmed.2017.1419.

33. Simonavicius E, McNeill A, Shahab L, Brose LS. Heat-not-burn tobacco products: a systematic literature review. Tob Control. 2018 2017;177(7):10501052; doi:10.1136/tobaccocontrol-2018-054419 doi: 10.1001/jamainternmed. 2017.1419.

34. Kong G, Kuguru KE, Krishnan-Sarin S. Gender differences in U.S. adolescent E-cigarette use. Curr Addict Rep. 2017;4(4):422-30. https://doi.org/10.1007/ s40429-017-0176-5.

35. Larson NI, Story M, Perry CL, Neumark-Sztainer D, Hannan PJ. Are diet and physical activity patterns related to cigarette smoking in adolescents? Findings from project EAT. Prev Chronic Dis. 2007:4(3):A51.

36. Keski-Rahkonen A, Kaprio J, Rissanen A, Virkkunen M, Rose RJ. Breakfast skipping and health-compromising behaviors in adolescents and adults. Eur J Clin Nutr. 2003;57(7):842-53. https://doi.org/10.1038/s.ejcn.1601618.

37. Dunbar MS, Tucker JS, Ewing BA, et al. Frequency of E-cigarette use, health status, and risk and protective health behaviors in adolescents. J Addict Med. 2017;1 1(1):55-62. https://doi.org/10.1097/ADM.0000000000000272.

38. Lee A, Lee KS, Park H. Association of the Use of a Heated Tobacco Product with Perceived Stress, Physical Activity, and Internet Use in Korean Adolescents: A 2018 National Survey. Int J Environ Res Public Health. 2019; 16(6). https://doi.org/10.3390/ijerph16060965.

39. Wills TA, Knight R, Williams RJ, Pagano I, Sargent JD. Risk factors for exclusive ecigarette use and dual e-cigarette use and tobacco use in adolescents. Pediatrics. 2015;135(1):e43-e51. doi: 10.1542\%2Fpeds.2014-0760.

40. Wills TA, Sargent JD, Gibbons FX, Pagano I, Schweitzer R. E-cigarette use is differentially related to smoking onset among lower risk adolescents. Tob Control. 2016;26(5):534-9. https://doi.org/10.1136/tobaccocontrol-2016053116

41. Goniewicz ML, Lingas EO, Hajek P. Patterns of electronic cigarette use and user beliefs about their safety and benefits: an internet survey. Drug Alcohol Rev. 2013;32(2):133-40. https://doi.org/10.1111/.1465-3362.2012.00512.

\section{Publisher's Note}

Springer Nature remains neutral with regard to jurisdictional claims in published maps and institutional affiliations. 